\title{
High-pressure air blasting experiments on concrete and implications for enhanced coal gas drainage
}

\author{
W.C. Zhu ${ }^{\mathrm{a} *}$, D. Gai ${ }^{\mathrm{a}}$, C.H.Wei ${ }^{\mathrm{a}}$, S.G. Li ${ }^{\mathrm{b}}$ \\ ${ }^{a}$ Key Laboratory of Ministry of Education on Safe Mining of Deep Metal Mines, Northeastern University, \\ Shenyang, 110819, China \\ ${ }^{b}$ Shenyang Research Institute, Fushun, China Coal Technology \& Engineering Group, 113122, China
}

\begin{abstract}
High-pressure air blasting is one type of distressing blasting techniques to enhance gas drainage in coal seams and thus to prevent coal and gas outbursts. In this work, firstly, high-pressure air blasting experiment is conducted on concrete specimen with a size of $600 \mathrm{~mm} \times 600 \mathrm{~mm} \times 600 \mathrm{~mm}$, the blasting crack distribution is observed and the particle vibration acceleration at the outer boundary of the sample is monitored. Then a damage model for high-pressure air blasting is proposed when the loading induced by high-pressure air blasting is considered as two consecutive stages, i.e. the dynamic loading stage induced by the stress wave and the quasi-static loading stage induced by quasi-static air pressure. Based on the experimental curve of particle vibration acceleration and corresponding numerical simulation, the stress wave distribution with Gaussian form around the borehole is inversed. In addition, the blasting induced damage evolution in the concrete specimen is numerically simulated, and the numerical result of final cracking pattern compares favorably with the experimental observation. During the high-pressure air blasting on concrete block, the blasting stress wave initiates primarily radial cracks and the crushed zone, and the quasi-static air pressure results in the extension of existing cracks and the expansion of crushed zone. Compared to the hydraulic fracturing with water, the high-pressure air blasting induces more fractures, which would be of great benefit to the enhanced gas drainage in coal seam. Finally, by considering the effect of coal seam damage on permeability, the gas drainage that may be enhanced by high-pressure air blasting is quantified based on the numerical simulations. It is demonstrated the damage induced by high-pressure air blasting around the borehole enhances the gas drainage dramatically; however the in-situ stress in coal seam may retrain the blasting-induced fractures and subsequent gas drainage, which should be paid attention to during the design of enhanced gas drainage with high-pressure air blasting.
\end{abstract} Keywords: high-pressure air blasting; gas drainage; blasting damage; damage model; numerical simulation

* Corresponding author, Tel.: +86-24-83687705; fax: +86-24-83681186, zhuwancheng@ mail.neu.edu.cn 


\section{Introduction}

The mining depths of some coal mines in China have now reached between $800 \mathrm{~m}$ and $1200 \mathrm{~m}$, and the gas pressure can reach $6 \mathrm{MPa}$, resulting in an increase of gas disasters, especially coal and gas outburst disasters (Lin et al., 2015; Liu et al., 2014). On the other hand, the gas drainage from coal seam in China is generally affected by the complex geological conditions, such as low permeability. So the hydraulic fracturing, water jetting and distress blasting are usually implemented to increase the permeability. However, the conventional water-based fracturing treatments do not perform up to potential in many gas reservoirs due to the productivity impairment, of which the major cause is the water retention effects (Al-Anazi, 2002; Mahadevan, 2007; Parekh, 2004). In many gas formations, water from the conventional water-based fracturing fluids will be trapped in the near-wellbore region during the fracturing processes, which can be very detrimental to the ability of gas to flow to the wells. Additionally, many gas-rich areas suffer from the water deficiency and the water supply may also limit the use of water-based fracturing fluids. Therefore, the gas fracturing is considered to be potentially efficient for enhanced coal gas and shale gas extraction.

Explosive blasting, high energy gas fracturing and high-pressure air blasting are three types of distress blasting techniques used in mining and related engineering sectors. Explosive blasting is used widely in hard-rock mining, coal mining as well as coal fracturing to enhance gas drainage. High energy gas fracturing (HEGF) is a technique to stimulate wellbores by producing several radial cracks around the holes by high pressure gas produced from burning a propellant, which is mainly used in oil and gas production and has now been successfully implemented in other applications such as coal seam gas extraction (Goodarzi et al., 2015). High-pressure air blasting is a technique first used in coal mining to fragmentize coal by high pressure air produced from air compressor. In this study, the failure mechanism of coal-like materials under the high-pressure air blasting will be studied, in order to clarify the associated mechanism with the permeability enhancement.

The mechanical mechanism of crack initiation and propagation induced by explosive blasting and high energy gas fracturing has been comprehensively studied (Kutter and Fairhurst, 1971; McHugh, 1983; Nilson et al., 1985; Fourney et al., 1993; Plaine and Please, 1994; Donze et al., 1997; Cho et al., 2004; Ma and An, 2008; Mohammadi and Pooladi, 2012; Goodarzi et al., 2015). According to these studies, one can conclude that the blasting process has two major stages which contribute to crack propagation and rock fragmentation, first a stress wave, followed by longer duration gas pressurization. The role of the stress wave is to create initial cracks, while the gas pressure can squeeze into the cracks and lead to crack extension (Donze et al., 1997; Mohammadi 
and Pooladi, 2012; Goodarzi et al., 2015). And the main differences between the explosive blasting and high energy gas fracturing lie in the peak pressure and duration time of the stress wave (Jaimes et al., 2012). In general, similar to explosive blasting, the mechanical response induced by high-pressure air blasting could be classified into two consecutive stages: dynamic loading stage by rapid rising of gas pressure which causes the crushed zone and cracks around the hole, and quasi-static loading stage by the quasi-static gas penetration which leads to the increase of the crushed zone radius and the extension of existing cracks (Donze et al., 1997; Zhu et al., 2013; Goodarzi et al., 2015). However, the mechanical mechanism of crack initiation and propagation induced by high-pressure air blasting and resultant enhancement of permeability are still unclear. Therefore, establishing a damage model for high-pressure gas blasting and clarifying the mechanism of enhanced permeability define the objective of this study.

In view of this, high-pressure air blasting experiment for man-made concrete specimen is done first. Then, a damage model of brittle material under high-pressure air blasting, consisting of two consecutive stages, i.e. the dynamic damage caused by the stress wave and the static damage caused by quasi-static air pressure is proposed, based on which numerical simulations on the high-pressure air blasting experiment is conducted and the model is validated. Finally numerical simulation on gas drainage in coal specimen after high-pressure air blasting is carried out to demonstrate the effect of high-pressure air blasting induced damage on the permeability increment and subsequent gas drainage enhancement.

\section{High-pressure air blasting experiment}

Considering the difficulty in preparing large-size coal sample, concrete blocks with size of $600 \mathrm{~mm} \times 600$ $\mathrm{mm} \times 600 \mathrm{~mm}$ are used for high-pressure air blasting experiments. There is a hole with a diameter of $75 \mathrm{~mm}$ at the center of the concrete block. The physico-mechanical parameters of concrete samples are listed in Table 1. This uniaxial compressive test and Brazilian test on the concrete specimen with the same mixture confirms that it is brittle and could be used for simulate the natural coal.

The test set-up is shown in Fig. 1. Through air compressor and booster pump, the air (atmosphere) is compressed to a maximum pressure of $100 \mathrm{MPa}$ and then stored in high pressure gasholder. The uniaxial compressive strength of the concrete samples is about $20 \mathrm{MPa}$; high-pressure air of $40 \mathrm{MPa}$ is used in the experiments. Through a switch and pipe, the high pressure gasholder is connected to the blasting cartridge which has been inserted into the borehole. One type of high-strength gypsum is used for sealing the borehole. As soon as the switch is turned on, the high-pressure air is sharply released and it flows into the borehole to 
fragmentize the concrete block. During the experiment, the particle vibration accelerations at the outer boundary of the sample are monitored.

Fig. 2(a) shows an intact concrete block before blasting. After re-arrangement of the fragments, we finally found the blasting induced cracks distribution as shown in Fig. 2(b-f). A crushed zone is created around the hole, expanding diameter of the hole and 5 to 6 primary radial cracks are produced. Compared to the hydraulic fracturing with water, the high-pressure air blasting induces more fractures, suggesting that it would be of great benefit to the enhanced gas drainage in coal seam.

\section{Governing equations}

\subsection{Material heterogeneity}

In order to characterize the heterogeneity of geomaterials, the domain is discretized into finite elements, whose mechanical parameters such as Young's modulus and strength are assigned according to the Weibull distribution as defined in the following probability density function (Zhu and Tang, 2004; Zhu et al., 2013):

$$
f(u)=\frac{m}{u_{0}}\left(\frac{u}{u_{0}}\right)^{m-1} \exp \left(-\left(\frac{u}{u_{0}}\right)^{m}\right)
$$

where $u$ is the parameter of the element; $u_{0}$ is the scale parameter related to the average of the material parameters, and the shape parameter $m$ is defined as a homogeneity index.

\subsection{Mechanical equilibrium and damage evolution equations}

In this study, it is assumed that two types of loading conditions applied on the borehole wall during high-pressure air blasting, first dynamic stress wave with short duration, followed by quasi-static gas pressurization with longer duration. In this regard, a momentum conservation equation for stress wave propagation and quasi-static gas pressurization is used. What is more, conservation equation for mass is derived on the macroscopic scale (all variables are averaged over the REV of the medium).

The modified Navier's equation is used to express the mechanical equilibrium in rock subjected to dynamic loading and quasi-static air pressure (Zhu et al., 2011),

$$
G u_{i, j j}+\frac{G}{1-2 v} u_{j, j i}+\alpha p_{, i}+F_{i}=\rho_{\mathrm{s}} \frac{\partial^{2} u_{i}}{\partial t^{2}}
$$

where $G$ is shear modulus $(\mathrm{Pa}), u_{i}(i=x, y, z)$ is displacement $(\mathrm{m}), v$ is the Poisson's ratio, $\alpha$ is Biot's coefficient, $F_{i}$ is the components of the net body force in the $i$-direction $\left(\mathrm{N} / \mathrm{m}^{3}\right), \rho_{\mathrm{s}}$ is solid density $\left(\mathrm{kg} / \mathrm{m}^{3}\right)$ and $t$ is time (s). During the dynamic loading stage, the term $\alpha p_{, i}$ would be zero. Druing the quasi-static 
gas pressurization stage, $p$ represents air pressure (Pa) and the right-hand term $\rho_{\mathrm{s}} \frac{\partial^{2} u_{i}}{\partial t^{2}}$ would be zero. During gas drainage process after high-pressure air blasting, $p$ represents coal gas pressure $(\mathrm{Pa})$ and the right term $\rho_{\mathrm{s}} \frac{\partial^{2} u_{i}}{\partial t^{2}}$ would also be zero. In this respect, since the flow of coal gas is very slow, it is only considered in the numerical analysis at quasi-static stage.

The maximum tensile stress criterion and Mohr-Coulomb criterion are used here to judge the tensile and shear damage for brittle rock(Zhu and Tang, 2004; Zhu et al., 2013), as expressed by

$$
F_{1} \equiv \sigma_{1}-f_{t 0}=0 \text { or } F_{2} \equiv-\sigma_{3}+\sigma_{1} \frac{1+\sin \varphi}{1-\sin \varphi}-f_{c 0}=0
$$

The elastic modulus would degrades as damage occurs, it reads,

$$
E=(1-D) E_{0}
$$

And according to Fig.3, the damage variable $D$ is defined as (Zhu and Tang, 2004; Zhu et al., 2013),

$$
D=\left\{\begin{array}{cccc}
0 & F_{1}<0 & \text { and } & F_{2}<0 \\
1-\left|\varepsilon_{t 0} / \varepsilon_{1}\right|^{n} & F_{1}=0 & \text { and } & d F_{1}>0 \\
1-\left|\varepsilon_{c 0} / \varepsilon_{3}\right|^{n} & F_{2}=0 & \text { and } & d F_{2}>0
\end{array}\right.
$$

\subsection{Gas flow equation}

The conservation equation for mass is derived on REV at the macroscopic scale for the geo-materials. The geo-material is composed of a solid matrix that contains interstitial pore space. The high-pressure air can then flow into the cracks and pore, causing the existing crack propagate further.

Gas flow in a porous medium is governed by a mass balance equation (Zhu et al., 2011),

$$
\frac{\partial}{\partial t}\left(\phi \rho_{g}\right)+\nabla \cdot\left(\rho_{g} \mathbf{q}_{g}\right)=Q_{s}
$$

where $\phi$ is porosity of crack or pore, $\rho_{g}$ is gas density $\left(\mathrm{kg} \cdot \mathrm{m}^{-3}\right), \mathbf{q}_{g}$ is Darcy velocity of the gas phase $\left(\mathrm{m} \cdot \mathrm{s}^{-1}\right), Q_{s}$ is a source term $\left(\mathrm{kg} \cdot \mathrm{m}^{-3} \cdot \mathrm{s}^{-1}\right)$ and $t$ is time (s). Gas density is given as,

$$
\rho_{g}=\frac{p}{p_{a}} \rho_{g a}
$$

where $p_{a}$ and $\rho_{g a}$ are pressure $(\mathrm{Pa})$ and density $\left(\mathrm{kg} \cdot \mathrm{m}^{-3}\right)$ of gas at standard conditions. 
Assuming that the effect of gravity is small in comparison to the induced pressure gradient, the Darcy velocity, $\mathbf{q}_{g}$, is given by,

$$
\mathbf{q}_{g}=-\frac{k}{\mu} \nabla p
$$

where $k$ is the permeability of the medium $\left(\mathrm{m}^{2}\right)$ and $\mu$ is the dynamic viscosity of the gas (Pa.s). Substituting Eqs. (7)-(8) into Eqn.(6), we obtain

$$
\phi \frac{\partial p}{\partial t}-\nabla \cdot\left(\frac{k}{\mu} p \nabla p\right)=\frac{p_{a}}{\rho_{g a}} Q_{s}
$$

Eqn. (9) can be used to describe the air flow through cracks during high-pressure air blasting process.

As for gas flow in coal seam, the absorption or desorption of methane may occur when the methane pressure and porosity of coal seam are changed. When the absorbed methane is considered, the methane flow equation in coal seam can be written as (Zhu et al., 2007, 2013),

$$
\beta\left[\frac{\phi}{p}+\frac{2 a_{1} a_{2} \rho_{m s}}{1+a_{2} p}-\frac{a_{1} a_{2}^{2} \rho_{s} p}{\left(1+a_{2} p\right)^{2}}\right] \frac{\partial p^{2}}{\partial t}-\nabla\left(\beta \frac{k}{\mu} \nabla p^{2}\right)=Q_{s}
$$

where $\beta$ is a compressibility factor $\left(\mathrm{kg} \mathrm{m}^{-3} \mathrm{~Pa}^{-1}\right), a_{1}$ and $a_{2}$ are Langmuir's volume constant $\left(\mathrm{m}^{3} \mathrm{~kg}^{-1}\right)$ and pressure constant $\left(\mathrm{Pa}^{-1}\right)$, respectively.

The effect of stress conditions on porosity can be given as (Zhu et al., 2007)

$$
\phi=\left(\phi_{0}-\phi_{r}\right) \exp \left(\alpha_{\phi} \cdot \sigma_{v}\right)+\phi_{r}
$$

where $\phi_{0}$ is porosity at zero stress, $\phi_{r}$ is residual porosity at high stress, $\alpha_{\phi}$ is stress sensitivity coefficient and $\sigma_{v}$ is the effective mean stress.

Besides, the effect of damage on permeability can be given according to the following function:

$$
k=k_{0}\left(\phi / \phi_{0}\right)^{3} \exp \left(\alpha_{k} D\right)
$$

where $k_{0}$ is permeability at zero stress $\left(\mathrm{m}^{2}\right)$ and $\alpha_{k}$ is damage-permeability effect coefficient.

As stated above, during the dynamic loading stage, Eqn. (2) is used to obtain dynamic stress state and Eqn. (4) is used to solve the damage evolution. Then the solved damage variables and corresponding parameters, including elastic modulus, strength and permeability, are transferred to the numerical analysis at quasi-static gas pressurization stage. At quasi-static gas pressurization stage, Eqns. (9) and (2) will be 
used to calculate quasi-static air pressure and stress state, with acceleration term $\rho_{\mathrm{s}} \frac{\partial^{2} u_{i}}{\partial t^{2}}$ at right-hand of Eqn. (2) being zero. Eqn. (4) will be used again to obtain damage evolution. The final damage zone distribution obtained at quasi-static stage, together with the corresponding parameters, including porosity and permeability, are then transferred to the numerical analysis of coal gas drainage, during which Eqn. (9) or (10) will be used to simulate gas drainage process.

Eqns. (2), (3), (4) and (9) or (10) represent a set of fully coupled non-linear equations governing the coupled response of damaged porous medium. More details about the implementation of these non-linear PDEs with COMSOL Multiphysics (COMSOL AB, 2008) have been presented in previous publications (Zhu et al., 2007; 2011).

\section{Numerical simulations}

In this section, the proposed damage model is used to simulate the high-pressure air blasting experiment, in order to validate the numerical code. Then numerical simulation on gas drainage in coal seam is also carried out to examine the effect of high-pressure air blasting on permeability increase and gas drainage enhancement.

According to the high-pressure air blasting experiment described in section 2, the numerical specimen is 0.6 $\mathrm{m}$ in side length, with a $0.075 \mathrm{~m}$ diameter hole at the center, as shown in Fig. 4. The actual three-dimensional model is simplified as a plane strain problem in our numerical simulations in order to reduce the computation capacity, and the numerical specimen is assumed to be heterogeneous with its physico-mechanical parameters of elements specified according to a Weibull distribution, which has a homogeneity index of 6 . Its frictional angle and Poisson's ratio are assumed homogeneous, and they are specified as $33^{\circ}$ and 0.15 , respectively.

\subsection{Back analysis of the high-pressure air}

During the experiment, the peak air pressure is known as $40 \mathrm{MPa}$, which can be read directly on a pressure gauge connected to the pipeline. However, the accurate time-history of the air pressure on the borehole surface is unknown, since it should be dependent on mutual interaction between the air and concrete, being difficult to be measured. So the particle vibration acceleration measured at the outer boundary of the sample is used as an initial condition to back-analyze the possible waveform of air pressure. In this respect, three types of waveforms, i.e., triangle wave, sine wave and Gaussian wave with peak pressure of $40 \mathrm{MPa}$ and duration of 400 $\mu$ s, as shown in Fig. 5, are input into an elastodynamic finite element model for back-analysis. 
Fig. 6 gives the back-calculated particle vibration acceleration at the outer boundary of the sample when three types of input waveform are input, from which we can see that result for Gaussian waveform is smoother. Most importantly, Fig.7 shows that the numerical curve compares well with the measured one when the Gaussian waveform shown in Fig. 5(c) is input, which indicates that the application of Gaussian wave as input waveform is possible to simulate the physical experiments of high-pressure air blasting. Donze et al. (1997) also gives reasons for choosing a Gaussian time function in explosive simulations, i.e., a good control of the frequency content and the peak pressure is possible and the time integration for this source type is smooth. Therefore, the Gaussian waveform as shown in Fig. 5(c) is used in later numerical simulations.

\subsection{Damage zone induced by high-pressure air blasting}

The numerical simulation on high-pressure air blasting induced damage consists of two consecutive stages, i.e., the dynamic loading stage induced by stress wave and quasi-static loading stage induced by air pressurization. During the dynamic loading stage, the stress wave as shown in Fig. 5(c) is applied first on internal borehole surface at steps 1-50, with a time step of $20 \mu \mathrm{s}$, while during the quasi-static loading stage the quasi-static air pressure as shown in Fig.8 is applied later from steps 51 to 100 . As regards quasi-static air pressure curve as shown in Fig.8, the damage zone would not extend anymore when the air pressure begins to decrease after step 100. Therefore, the numerical simulation is only conducted from steps 51 to 100 .

Fig.9 shows the damage evolution induced at the dynamic loading stage, where the distributions of the major principle stress, minor principle stress, damage zone and Young's modulus are shown. The maximum principle stress distribution is shown in first row, where positive value for tension and negative value for compression. The damage zone distribution is shown in third row, where 0 for no damage, -1 for tensile damage and 1 for shear damage. As shown in the first and second rows in Fig.9, the stress wave is applied on internal borehole surface and spreads outward, resulting in compressive stress and tensile stress around the borehole. A crushed zone is created around the borehole. When the stress wave arrives at the outer boundary and reflects, tensile damage may occur near the boundary. As shown in the fourth row in Fig.9, the elastic modulus degrades monotonically as damage evolves.

Fig.10 shows the damage evolution induced by quasi-static air pressure at the quasi-static loading stage, where the permeability, air pressure, major principle stress, damage zone and Young's modulus distributions are presented. The permeability distribution is shown in the first row, where white indicates the damaged element with high permeability. It is seen that the permeability at damage zone, no matter tensile damage or shear damage, increases dramatically. In this respect, the air can squeeze into the cracks depending not only on the 
permeability enhancement, but on the connectivity between damage zones. As shown in the second row in Fig. 10, air mainly squeezes into the crushed zone and primary radial cracks rather than the discrete damage points.

From the major principle stress distribution as shown in the third row in Fig.10, we can see that the air can squeezes into the connected cracks and cause tensile stress concentration at the crack tips, resulting in the extension of existing cracks which in turn provides new flow channels for the air flow. In this way, the air squeeze into the cracks and the cracks expands further, leading to the formation of the 5 primary radial cracks and the final failure of the sample.

It is seen from the damage zone or Young's modulus distribution at step 100 in Fig. 10 that the high-pressure air blasting induced cracks distribution compares well with the experimental observation as shown in Fig. 2(b). Thus, it is reasonable to conclude that the proposed model is effective in capturing the damage process and cracks evolution during high-pressure air blasting.

Fig.11 shows the development of damage zone area during the high-pressure air blasting. During the dynamic loading stage, the damage zone area undergoes a process from slowly increasing (steps 1 to 8 ) to rapidly increasing (steps 9 to 34), until a final stable stage (steps 35 to 50). At the quasi-static air pressure stage, the damage zone area also undergoes a process from slowly increasing (steps 51 to 69) to rapidly increasing (steps 70 to 95 ) and finally stable stage (steps 96 to 100). The damage zone areas at the end of dynamic loading stage and quasi-static loading stage are $0.063 \mathrm{~m}^{2}$ and $0.076 \mathrm{~m}^{2}$, respectively. Although the damage zone area produced at quasi-static loading stage is $0.013 \mathrm{~m}^{2}$, accounting for only $17 \%$ of the final damage area, it plays a vital role on the formation of primary radial cracks.

\section{The effect of high-pressure air blasting on gas drainage from coal}

In this section, numerical simulation on gas drainage from coal is carried out further to demonstrate the effect of high-pressure air blasting induced damage on the permeability enhancement. The numerical specimen is $3 \mathrm{~m}$ in side length, with a $0.075 \mathrm{~m}$ diameter hole at the center, as shown in Fig.12. During the dynamic loading stage, stress wave $p_{d}$ is applied around the hole and the external boundary is far enough that the stress wave does not arrive at the boundary throughout the duration of computation. During the quasi-static loading stage, air pressure $p_{g}$ is applied around the hole and in-situ stress boundary $\sigma_{\mathrm{bx}}$ and $\sigma_{\mathrm{by}}$ are applied to the external boundary. Its physico-mechanical parameters is specified according to a typical coal experimented by other researchers (An et al., 2013; Pan et al., 2013; Hu et al., 2015), as listed in Table 2. 


\subsection{Gas drainage without considering in-situ stress}

Firstly, damage evolution of coal specimen induced by high-pressure air blasting without in-situ stress is numerically simulated. The dynamic stress wave as shown in Fig. 5(c) and the quasi-static air pressure as shown in Fig.8 are applied as boundary loading, respectively. Fig.13 shows the final damage zone, Young's modulus and permeability distributions after the blasting (at step 100). Then, permeability distribution after blasting as shown at step 100 in Fig.13 is specified for numerical simulation of gas drainage in coal. The initial gas pressure in the specimen is assumed to be $5 \mathrm{MPa}$. The external boundary is insulated for gas flow. For the wellbore, methane pressure $p_{\mathrm{w}}$ is $0.1 \mathrm{MPa}$. Eqn. (9) is used here to describe the free gas flow process without absorbed gas considered.

Fig. 14 shows the gas pressure distribution in the specimen at different time scales before and after blasting. When the gas is drained before blasting, the gas would flow radially into the borehole. After blasting the gas would flow firstly from the matrix or micro-pore into the fractures induced by blasting and then flow from the fractures into the borehole, reflecting the faster gas drainage due to the distress blasting.

The specimen after blasting is a typical dual porosity/permeability system containing porous matrix surrounded by fractures. The free gas flow process would be affected by the permeability of both matrix and fractures. Therefore, different permeabilities of matrix and fracture are specified in the numerical simulation in order to examine their effect on gas drainage.

Fig. 15 shows the gas content in the specimen at $t=20$ days after drainage. In Fig. 15(a), the initial matrix permeability is $1 \times 10^{-15} \mathrm{~m}^{2}$, while the fracture permeability from $1 \times 10^{-14} \mathrm{~m}^{2}$ to $1 \times 10^{-11} \mathrm{~m}^{2}$ is specified. At $t=20$ days, the gas content reduces to $97.8 \%, 93.7 \%, 90.4 \%$ and $89.8 \%$ for the fracture permeability of $1 \times 10^{-14} \mathrm{~m}^{2}$, $1 \times 10^{-13} \mathrm{~m}^{2}, 1 \times 10^{-12} \mathrm{~m}^{2}$ and $1 \times 10^{-11} \mathrm{~m}^{2}$, respectively. It indicates that the increment of fracture permeability can enhance the gas drainage until fracture permeability of $1 \times 10^{-12} \mathrm{~m}^{2}$, after which the further increment of fracture permeability would not be able to enhance the gas drainage significantly. This indicates that under this condition, the matrix permeability is a primary factor affecting the gas drainage.

Therefore, in Fig. 15(b), the blasting induced fracture permeability is specified as $1 \times 10^{-12} \mathrm{~m}^{2}$, while the initial matrix permeabilities from $1 \times 10^{-16} \mathrm{~m}^{2}$ to $1 \times 10^{-13} \mathrm{~m}^{2}$ are applied, respectively. At $t=20$ days, the gas content reduce to $94.2 \%, 90.4 \%, 80 \%$ and $54.1 \%$ for the fracture permeabilities of $1 \times 10^{-16} \mathrm{~m}^{2}, 1 \times 10^{-15} \mathrm{~m}^{2}$, $1 \times 10^{-14} \mathrm{~m}^{2}$ and $1 \times 10^{-13} \mathrm{~m}^{2}$, respectively. This indicates the further improve of the matrix permeability (from $1 \times 10^{-15} \mathrm{~m}^{2}$ to $1 \times 10^{-13} \mathrm{~m}^{2}$ ) can increase the gas productivity dramatically. 


\subsection{Gas drainage under in-situ stress condition}

In order to examine the effects of different in-situ stress on the damage evolution, a range of magnitudes of the lateral pressure coefficient $\lambda$ of $0.5,1$ and 2 , which defines the ratio between horizontal in-situ stress and vertical in-situ stress, are specified in the numerical simulation. Fig.16 shows the damage evolution, where the damage zone, Young's modulus, permeability and gas pressure after 4 hours of gas drainage are presented. When $\lambda$ is 0.5 , the damage-induced fractures in the horizontal direction is restrained, similarly, the fractures in the vertical direction is restrained for $\lambda$ of 2 , and the fractures in all directions are restrained for $\lambda=1$. What is more, for the same $\lambda$, the area of fractures decreases with the increasing in-situ stress, which implies that the suppression of in-situ stress on the initiation and propagation of blasting-induced fractures.

Fig. 17 shows the gas content in the coal specimen at $t=20$ days after drainage, from which we can see that the gas content at the same time increase with the in-situ stress, indicating the suppression of in-situ stress on blasting-induced fractures and subsequent gas drainage. In the regard, the permeability enhancement becomes more important for the gas extraction from coal seam at depth.

\section{Conclusions}

High-pressure air blasting is one type of destress blasting techniques to enhance gas drainage and thus to prevent coal and gas outbursts. It is of vital importance to understand the mechanism of damage zone development induced by high-pressure air blasting and consequent gas drainage enhancement. In this work, high-pressure air blasting experiments and numerical simulations are carried out and the following conclusions can be drawn:

(1) High-pressure air blasting experiments for concrete sample with size of $600 \mathrm{~mm} \times 600 \mathrm{~mm} \times 600 \mathrm{~mm}$ is done first. A total of six main cracks are induced, which results in final failure of the sample. The input stress wave pulse with a Gaussian time function is back-analyzed based on the monitoring of particle vibration acceleration at the outer boundary of the sample.

(2) Based on damage mechanics theory, a mechanical model for high-pressure air blasting in coal and geo-materials is established with considering of the material heterogeneity, in which blasting was considered as two consecutive stages, i.e. the dynamic loading stage caused by the stress wave and the quasi-static loading stage caused by quasi-static air pressurization.

(3) Numerical simulations on high-pressure air blasting experiments are conducted and the proposed numerical model is validated. The stress wave firstly initiates the crushed zone and the primary radial cracks. 
Then the quasi-static air squeeze in the existing crushed zone and cracks, resulting in the increase of the crushed zone radius and the extension of existing cracks. Finally a total of five main penetrating cracks are reproduced, leading to the final failure of the sample, which compares well with the experimental observation. Compared to the hydraulic fracturing with water, the high-pressure air blasting induces more fractures, which would be of great benefit to the enhanced gas drainage in coal seam. Thus, it is reasonable to conclude that the proposed model is effective in capturing the high-pressure air blasting induced damage process.

(4) Numerical simulations on gas drainage after high-pressure air blasting are carried out further. It is demonstrated that the blasting induced cracks can enhance the permeability and subsequent gas drainage dramatically. In this respect, the enhancement of gas drainage depends on many factors such as in-situ stress conditions, the numerical simulations indicate that the suppression of in-situ stress on blasting-induced fractures and subsequent gas drainage.

It should be noted that, in this study the high-pressure air blasting experiments are conducted with concrete specimen, it may be different with the real coal, therefore, the experiments on the coal sample or coal seam should be conducted in future. In addition, due to the limitation of computational capacity, the numerical simulations is conducted as $2 \mathrm{D}$ problem, in future, In future, parallel computing will be employed to do the 3D numerical simulations, in order effectively caputrue the relastic damage zone development and enhanced gas drainage in coal seam.

\section{Acknowledgements}

This work is funded by the National Major Scientific and Technological Special Project for "Development of large-scale oil \& gas and coal gas reservoir" during the $12^{\text {th }}$ Five-year Plan Period (Grant No.2011ZX05041-003), National Science Foundation of China (Grant Nos. 51304037, 51374049 and 51525402) and the Fundamental Research Funds for the Central Universities of China (Grant Nos. N140105001 and N140104007). These supports are gratefully acknowledged.

\section{References}

An, F. H., Cheng, Y. P., Wang, L., Li, W,. 2013. A numerical model for outburst including the effect of adsorbed gas on coal deformation and mechanical properties. Comput. Geotech.,54(10), 222-231.

Al-Anazi, H. A., Pope, G. A., Sharma M. M., Metcalfe, R. S., 2002. Laboratory measurements of condensate blocking and treatment for both low and high permeability rocks, SPE-77546-MS, SPE Annual Technical Conference and Exhibition, 29 September-2 October, San Antonio, Texas. 
Cho, S.H., Nakamura Y., Kaneko K., 2004. Dynamic fracture process analysis of rock subjected to stress wave and gas pressurization. Int. J. Min. Sci. Technol. 41, 433-440.

COMSOL AB, 2015. COMSOL Multiphysics Version 3.5, User's Guide and Reference Guide. (ww.comsol.com).

Donze, F.V., Bouchez, J., Magnier, S.A., 1997. Modeling fractures in rock blasting. Int. J. Rock Mech. Min. Sci. 34(8), 1153-1163.

Fourney, W. L., Dick, R. D., Wang, X. J., Wei Y., 1993. Fragmentation mechanism in crater blasting. Int. J. Rock Mech. Min. Sci. Geomech. Abstr. 30, 413-429.

Goodarzi, M., Mohammadi, S., Jafari, A., 2015. Numerical analysis of rock fracturing by gas pressure using the extended finite element method. Pet. Sci. 12(2), 304-315

Hu, S., Wang, E., \& Kong, X., 2015. Damage and deformation control equation for gas-bearing coal and its numerical calculation method. J. Nat. Gas Sci. Eng. 25, 166-179.

Jaimes, M.G., Castillo, R.D., Mendoza, S.A., 2012. High energy gas fracturing: a technique of hydraulic prefracturing to reduce the pressure losses by friction in the near wellbore-a Colombian field application. SPE 152886.

Kutter, H. K., Fairhurst, C., 1971. On the fracture process in blasting. Int. J. Rock Mech. Mix. Sci. 8, 181-202.

Lin, B.Q., Yan, F.A., Zhu, C.J., Zhou, Y., Zou, Q.L., Guo, C., Liu, T., 2015. Cross-borehole hydraulic slotting technique for preventing and controlling coal and gas outbursts during coal roadway excavation. J. Nat. Gas Sci. Eng. 26, 518-525.

Liu, Q.Q., Cheng, Y.P., Yuan, L., Tong, B., Kong, S.L., Zhang, R., 2014. CMM capture engineering and characteristics of in-situ stress distribution in deep level of Huainan coalfield. J. Nat. Gas Sci. Eng. 20, 328-336.

Ma, G.W., An, X.M., 2008. Numerical simulation of blasting-induced rock fractures. Int. J. Rock Mech. Min. Sci. 45, 966-975.

Mahadevan J., Sharma M. M. and Yortsos Y. C., 2007. Capillary wicking in gas wells, SPE Journal, 12, 429 $-437$.

Mohammadi, S., Pooladi, A., 2012. A two-mesh coupled gas flow-solid interaction model for 2D blast analysis in fractured media. Finite Elem. Anal. Des. 50, 48-69.

McHugh, S., 1983. Crack extension caused by internal gas pressure compared with extension caused by tensile stress. Int. J. Fract. 21, 163-176. 
Nilson, R.H., Proffer, W.J., DuffR. E., 1985. Modelling of gas-driven fractures induced by propellant combustion within an explosion cavity. Int. J. Rock Mech. Min. Sci. 22, 3-19.

Pan, J., Meng, Z., Hou, Q., Ju, Y., Cao, Y., 2013. Coal strength and young's modulus related to coal rank, compressional velocity and maceral composition. J. Struct. Geol.,54, 129-135.

Parekh B. and Sharma M. M., 2004. Cleanup of water blocks in depleted low-permeability reservoirs, SPE-89837-MS, SPE Annual Technical Conference and Exhibition, 26-29 September, Houston, Texas.

Plaine, A.S., Please, C. P., 1994. An improved model of fracture propagation by gas during rock blasting--some analytical results. Int. J. Rock Mech. Min. Sci. Geomech. Abstr. 31, 699-706.

Zhu, W.C., Tang, C.A., 2004. Micromechanical model for simulating the fracture process of rock. Rock Mech. Rock Eng. 37(1), 25-56.

Zhu, W.C., Liu, J., Sheng, J.C., Elsworth, D., 2007. Analysis of coupled gas flow and deformation process with desorption and Klinkenberg effects in coal seams. Int. J. Rock Mech. Min. Sci. 44(7), 971-980.

Zhu, W.C., Wei, C.H., Liu, J., Qu, H.Y., Elsworth, D., 2011. A model of coal-gas interaction under variable temperatures. Int. J. Coal Geol. 86(2-3), 213-221.

Zhu, W.C., Wei, C.H., Li, S., Wei, J., Zhang, M.S., 2013. Numerical modeling on destress blasting in coalseam for enhancing gas drainage. Int. J. Rock Mech. Min. Sci. 59, 179-190. 


\section{List of tables}

Table 1 The physico-mechanical parameters of concrete specimen

Table 2 The physico-mechanical parameters of coal seam

Table 1 The physico-mechanical parameters of concrete specimen

\begin{tabular}{lll}
\hline Parameters & Value & Unit \\
\hline Young's modulus, E & 3 & $\mathrm{GPa}$ \\
Poisson's ratio, $\mu$ & 0.15 & \\
Mass density, $\rho$ & 2500 & $\mathrm{~kg} / \mathrm{m}^{3}$ \\
Uniaxial compressive strength & 20 & $\mathrm{MPa}$ \\
\hline
\end{tabular}

Table 2 The physico-mechanical parameters of coal seam

\begin{tabular}{lll}
\hline Parameter & Value & Unit \\
\hline Young's modulus, $E$ & 2.5 & $\mathrm{GPa}$ \\
Poisson's ratio, $\mu$ & 0.3 & \\
Mass density, $\rho$ & 1400 & $\mathrm{~kg} / \mathrm{m}^{3}$ \\
Uniaxial compressive strength, $f_{c 0}$ & 10 & $\mathrm{MPa}$ \\
Porosity at zero stress, $\phi_{0}$ & 0.08 & $\mathrm{~m}^{2}$ \\
Residual porosity, $\phi_{r}$ & 0.01 & $\mathrm{~m}^{2}$ \\
Stress sensitivity coefficient, $\alpha_{\phi}$ & $5 \times 10^{-8}$ & $\mathrm{~Pa}^{-1}$ \\
Damage-permeability effect coefficient, $\alpha_{\kappa}$ & 10 & \\
Matrix permeability & $1 \times 10^{-15}$ & $\mathrm{~m}^{2}$ \\
Fracture permeability & $1 \times 10^{-12}$ & $\mathrm{~m}^{2}$ \\
\hline
\end{tabular}




\section{List of figures}

Fig.1 Experimental set-up for high-pressure air blasting on concrete specimen

Fig.2 Concrete specimen before and after high-pressure air blasting

Fig.3 The elastic damage-based constitutive law of elements under uniaxial stress condition $\left(f_{t 0}\right.$ and $f_{\mathrm{c} 0}$ are uniaxial tensile strength and uniaxial compressive strength, respectively.)

Fig.4 Numerical model setup for high-pressure air blasting on concrete specimen

Fig.5 Three types of waveforms used in numerical simulation of high-pressure air blasting in concrete specimen

Fig.6 Simulated particle vibration acceleration induced by the three types of waveform

Fig.7 Comparison of experimental and numerical results of particle vibration acceleration

Fig.8 Air pressure applied at the quasi-static loading stage for high-pressure air blasting in the numerical simulation

Fig.9 Damage evolution induced by stress wave at the dynamic loading stage (numerical results)

Fig.10 Damage evolution at the quasi-static loading stage (numerical results)

Fig.11 Development of damage zone area during high-pressure gas blasting (numerical results)

Fig.12 Model setup for permeability enhancement with high-pressure air blasting in coal seam

Fig.13 Numerical results of the final damage zone, Young's modulus and permeability distributions induced by high-pressure air blasting (at Step 100)

Fig.14 Gas pressure distribution in the sample at different time scales (numerical results)

Fig. 15 The relative gas content in the sample until 20 hours after drainage (numerical results)

Fig.16 Damage evolution induced by high-pressure air blasting when different confining pressures are specified (numerical results)

Fig.17 The relative gas content in the sample until 20 hours after drainage (numerical results) 


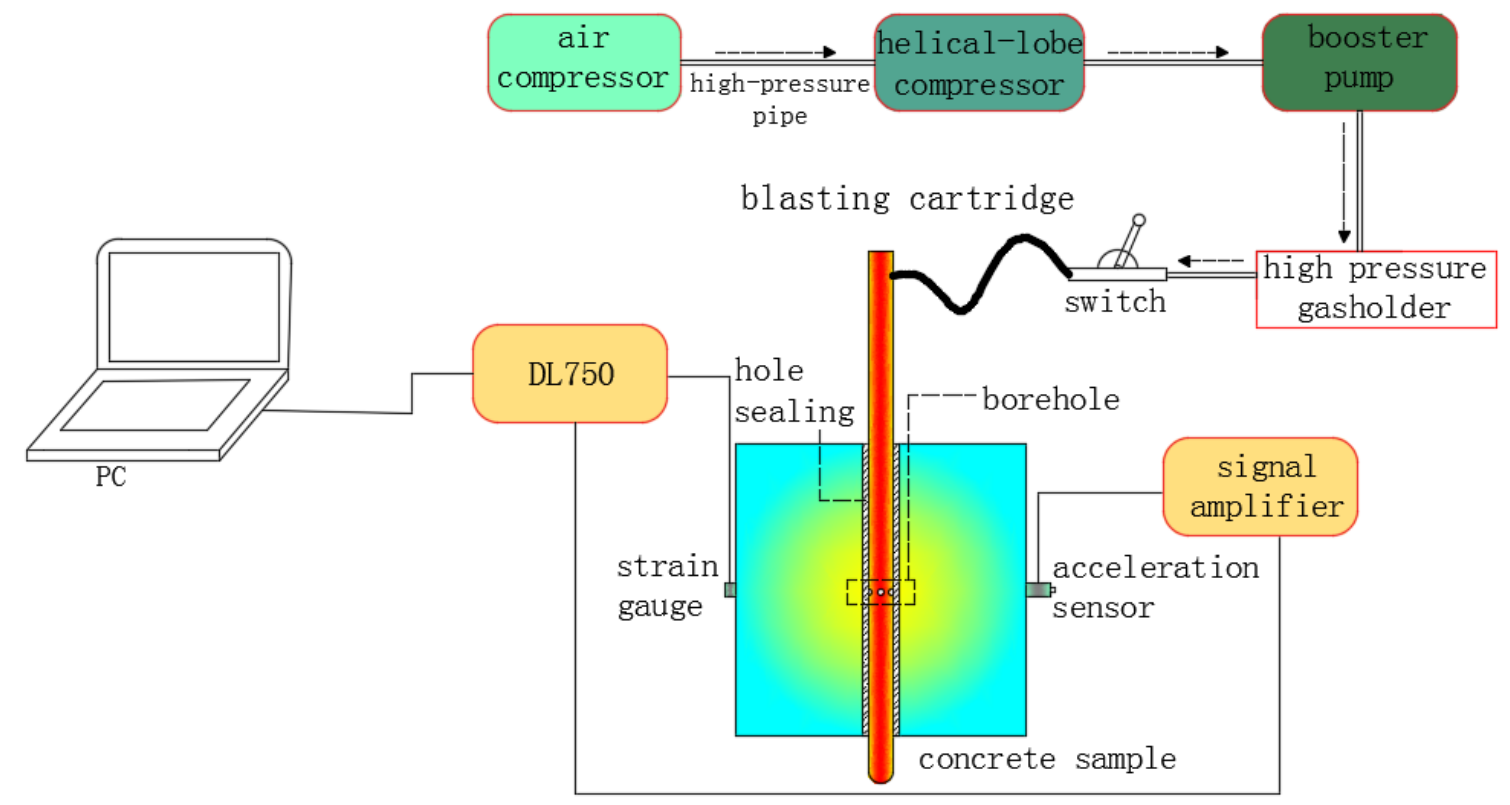

Fig. 1 Experimental set-up for high-pressure air blasting on concrete specimen 


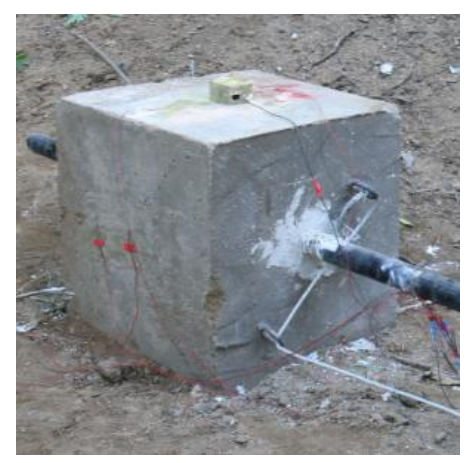

(a) Concrete specimen before blasting

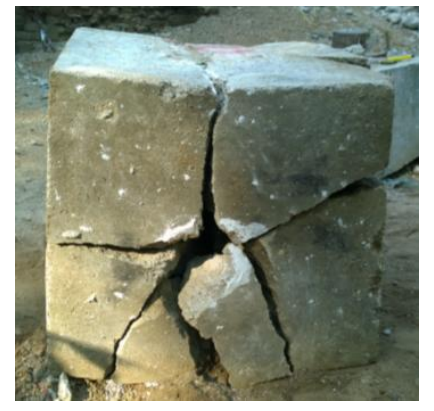

(b) Front view after blasting

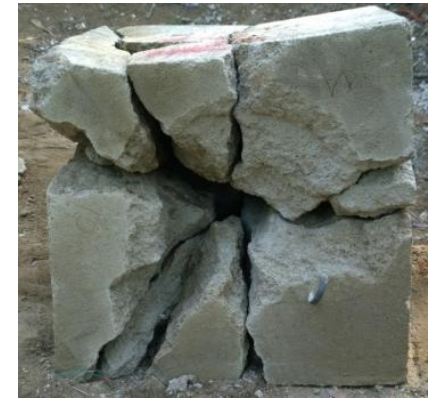

(c) Back view after blasting

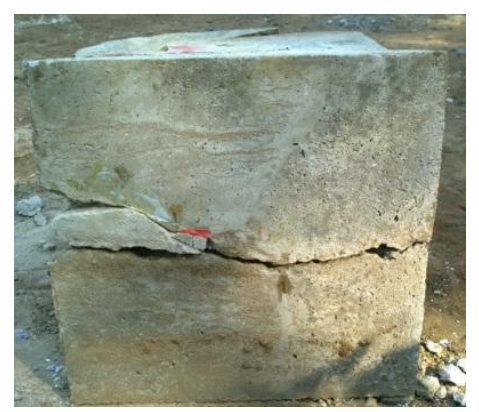

(d) Left view after blasting

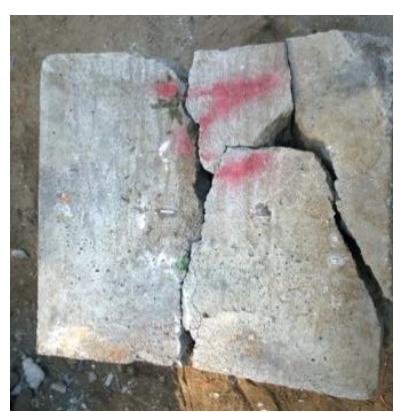

(e) Top view after blasting

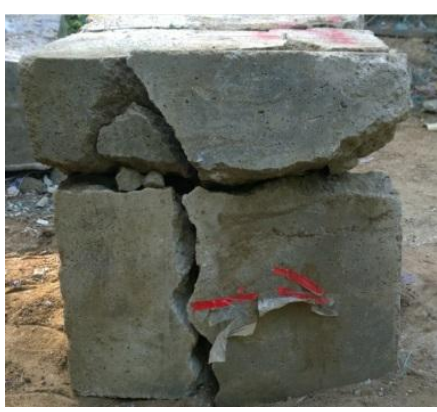

(f) Right view after blasting

Fig.2 Concrete specimen before and after high-pressure air blasting 


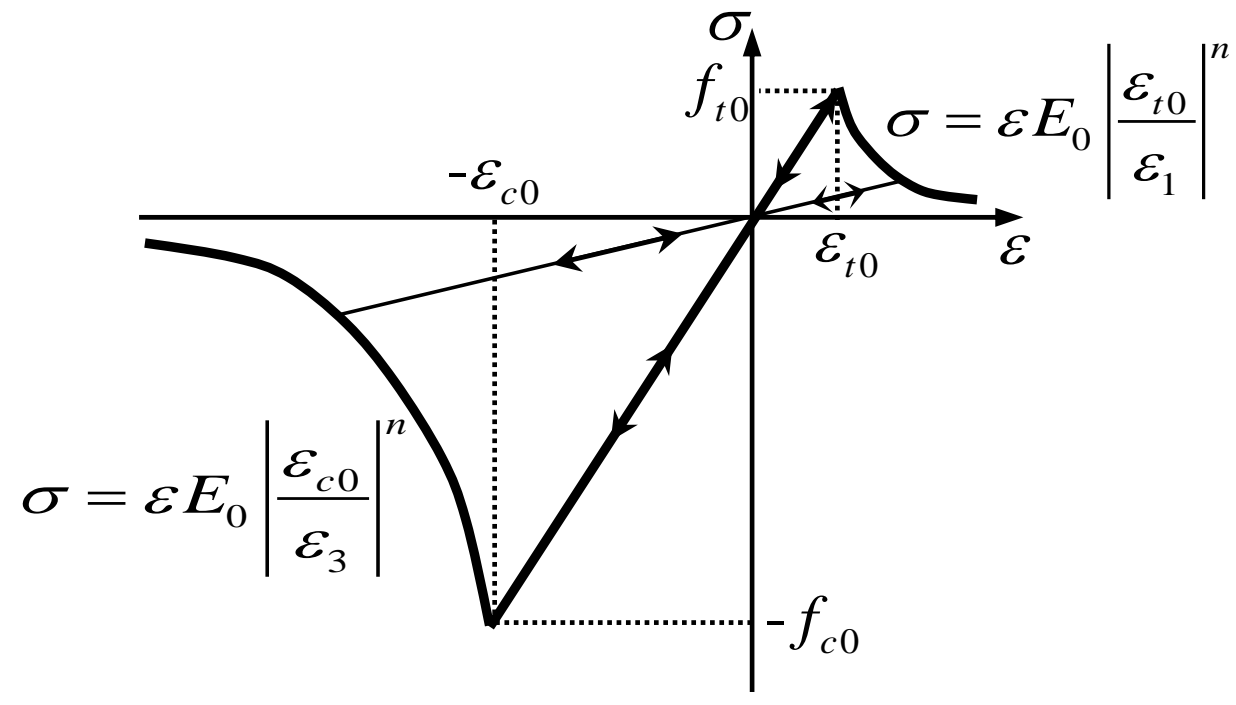

Fig.3 The elastic damage-based constitutive law of elements under uniaxial stress condition $\left(f_{\mathrm{t} 0}\right.$ and $f_{\mathrm{c} 0}$ are uniaxial tensile strength and uniaxial compressive strength, respectively.) 


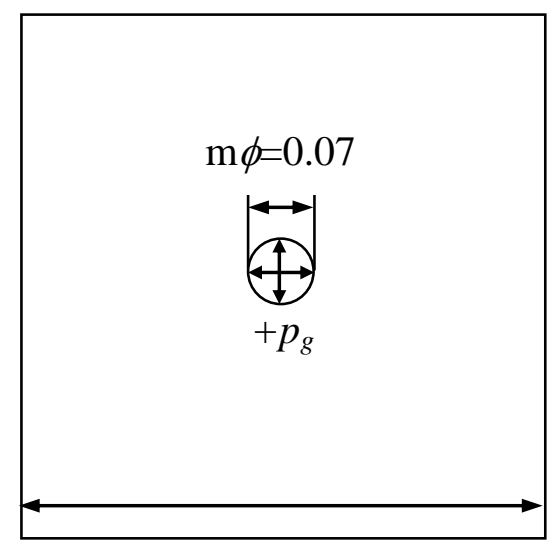

Fig.4 Numerical model setup for high-pressure air blasting on concrete specimen 


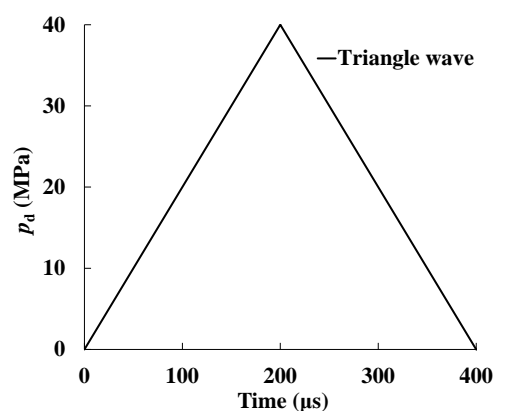

(a) Triangle wave

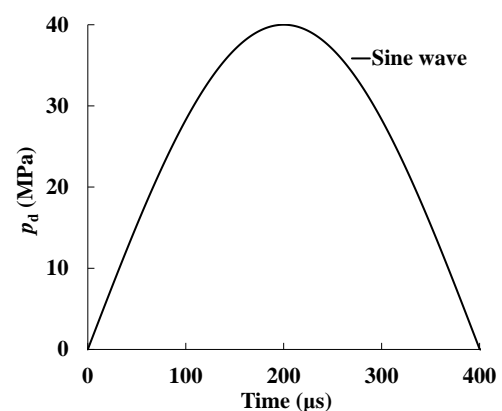

(b) Sine wave

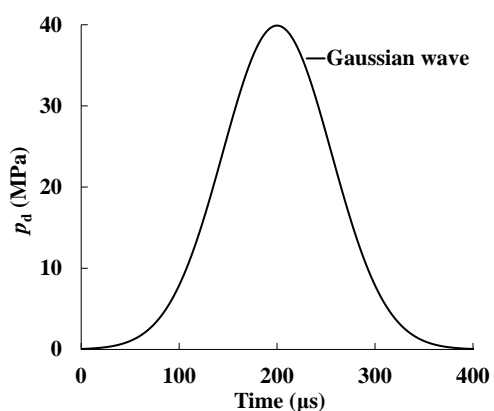

(c) Gaussian wave

Fig.5 Three types of waveforms used in numerical simulation of high-pressure air blasting in concrete specimen 


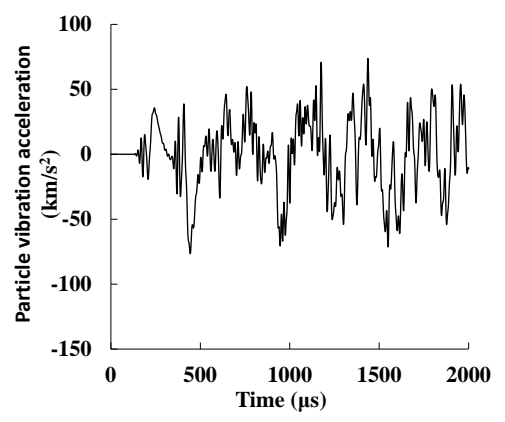

(a) Triangle wave

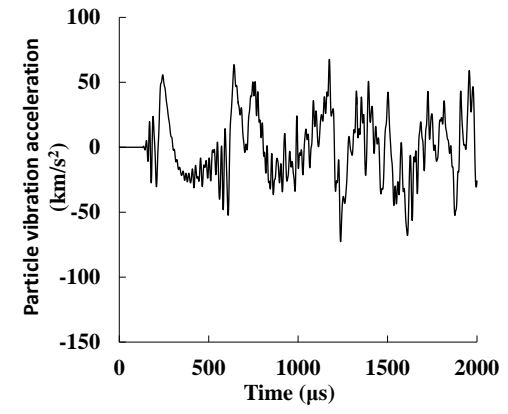

(b) Sine wave

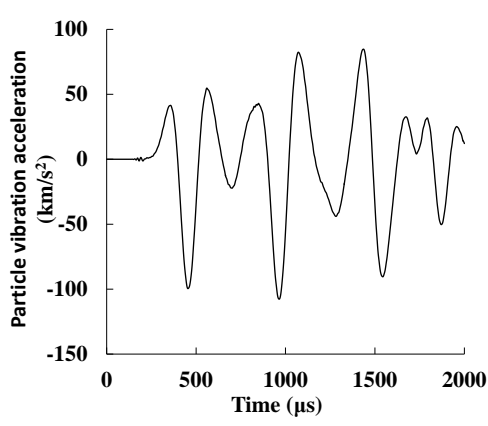

(c) Gaussian wave

Fig.6 Simulated particle vibration acceleration induced by the three types of waveform 


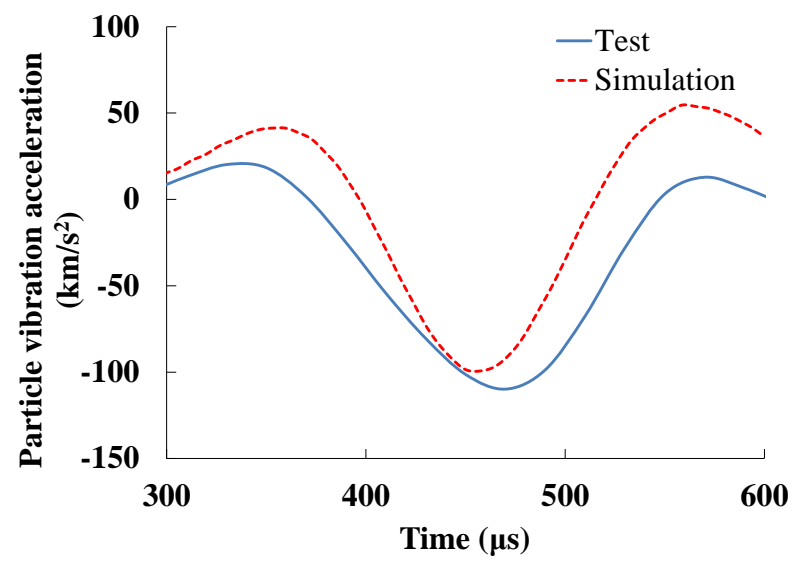

Fig.7 Comparison of experimental and numerical results of particle vibration acceleration 


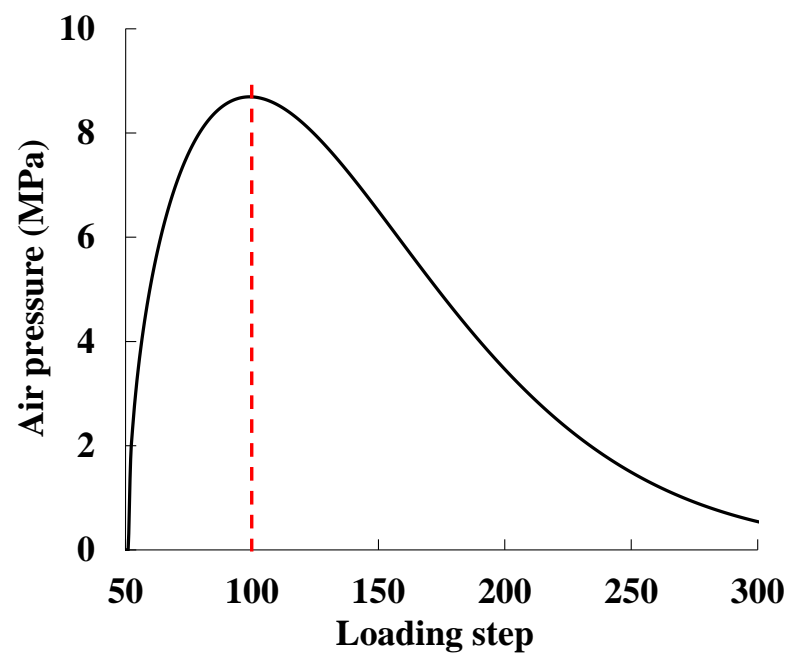

Fig.8 Air pressure applied at the quasi-static loading stage for high-pressure air blasting in the numerical simulation 


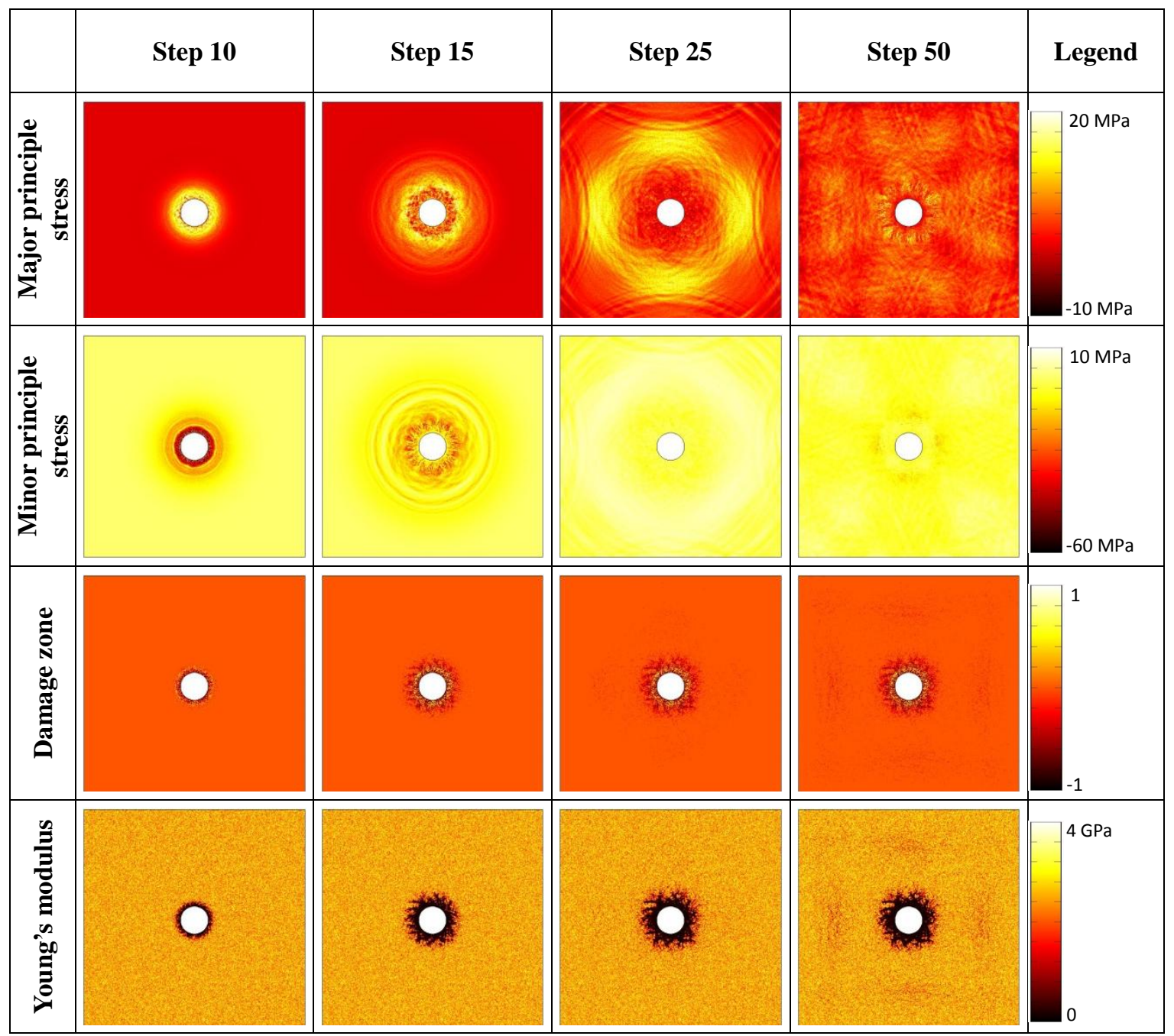

Fig.9 Damage evolution induced by stress wave at the dynamic loading stage (numerical results) 


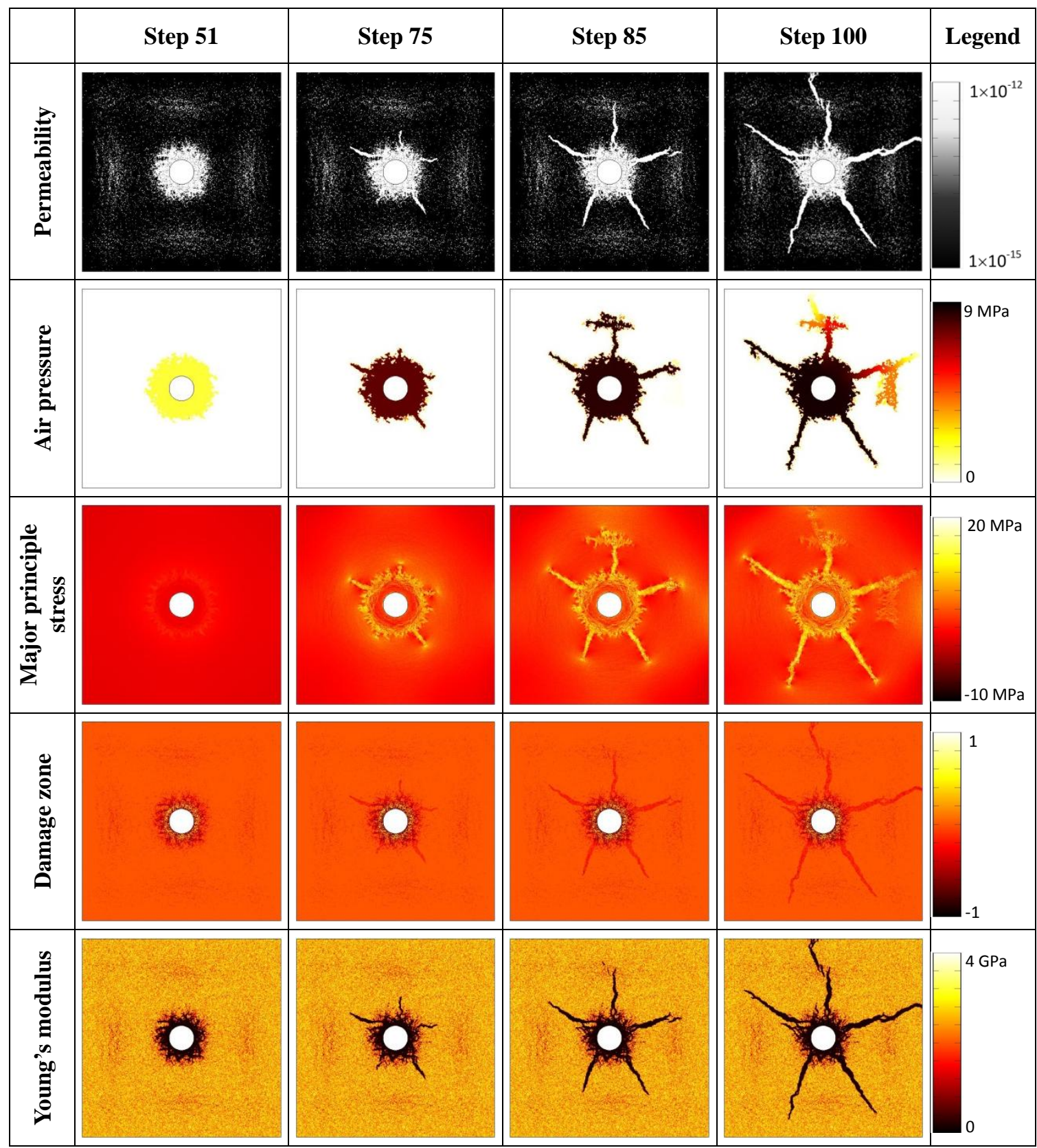

Fig.10 Damage evolution at the quasi-static loading stage (numerical results) 


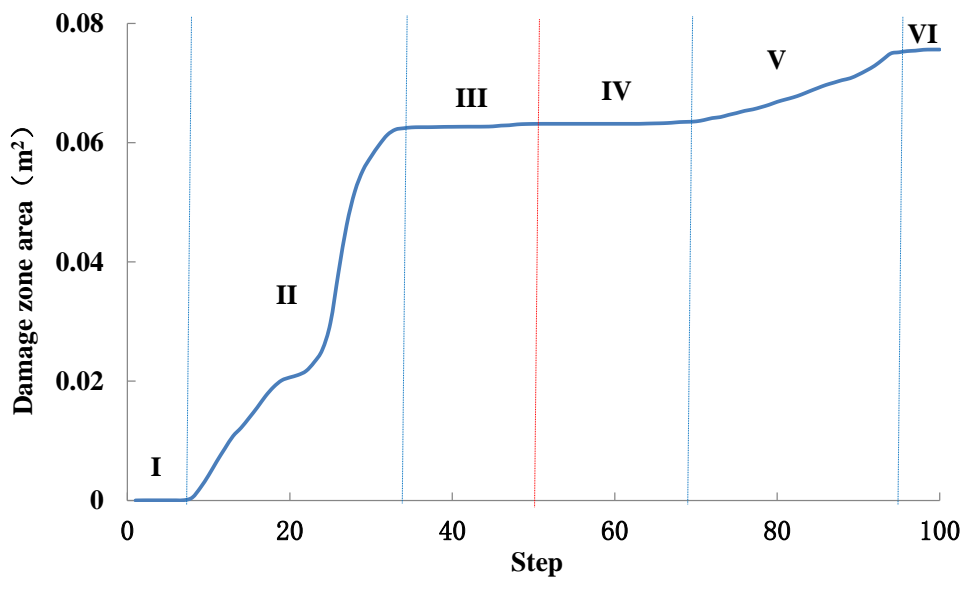

Fig.11 Development of damage zone area during high-pressure gas blasting (numerical results) 


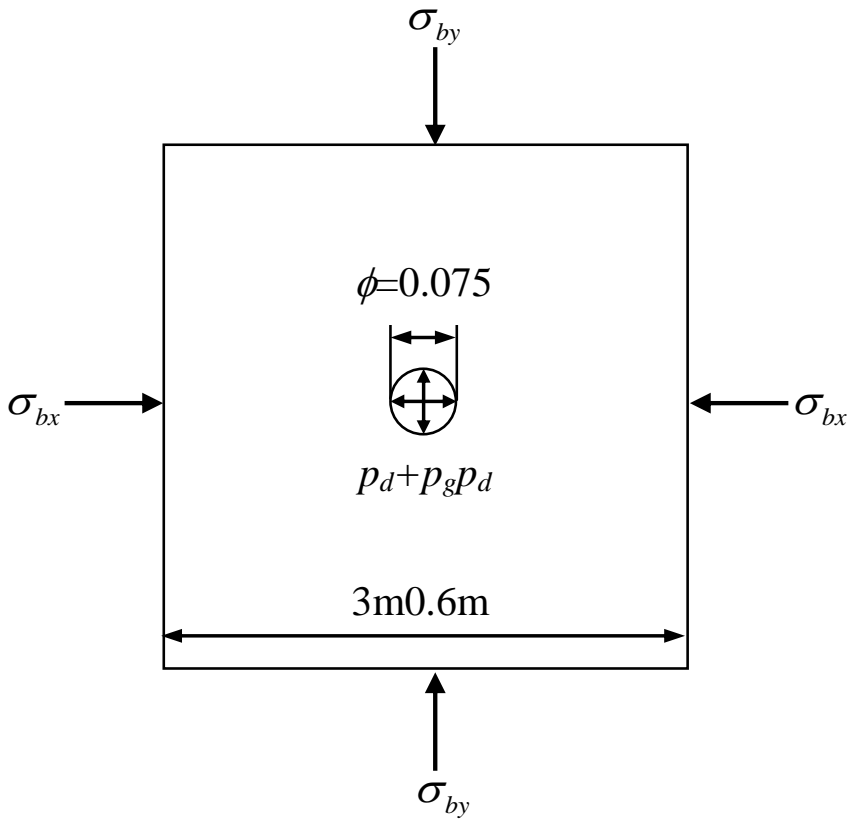

Fig.12 Model setup for permeability enhancement with high-pressure air blasting in coal seam 


\begin{tabular}{|l|l|l|l|}
\hline Damage zone & Young's modulus & Permeability \\
\hline & & & \\
& & &
\end{tabular}

Fig.13 Numerical results of the final damage zone, Young's modulus and permeability distributions induced by high-pressure air blasting (at Step 100) 


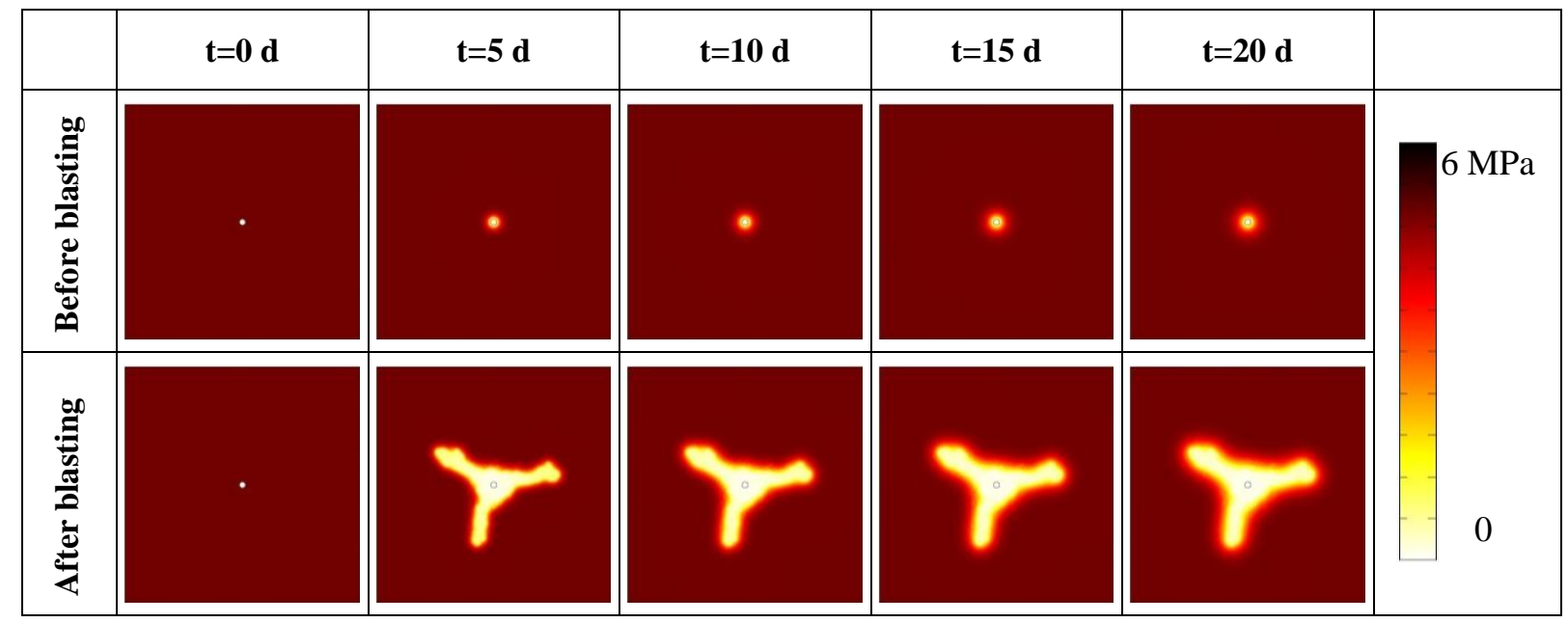

Fig.14 Gas pressure distribution in the sample at different time scales (numerical results) 


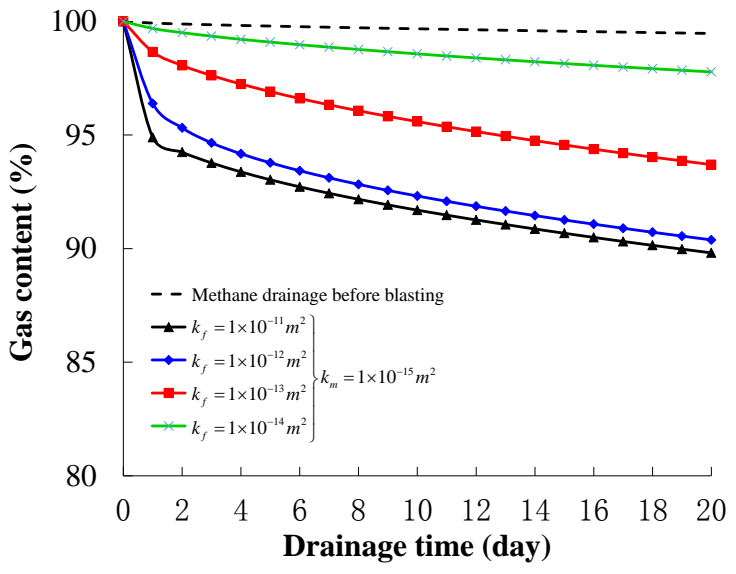

(a) Gas drainage for different fracture permeability

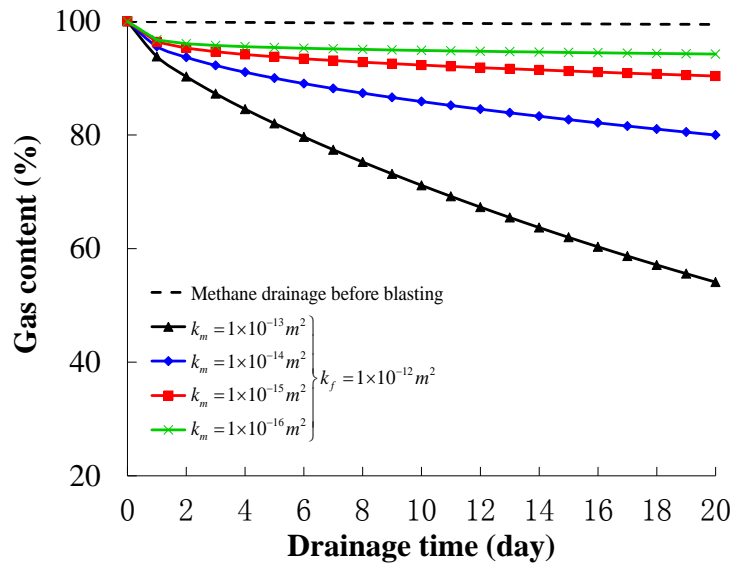

(b) Gas drainage for different matrix permeability

Fig.15 The relative gas content in the sample until 20 days after drainage (numerical results) 


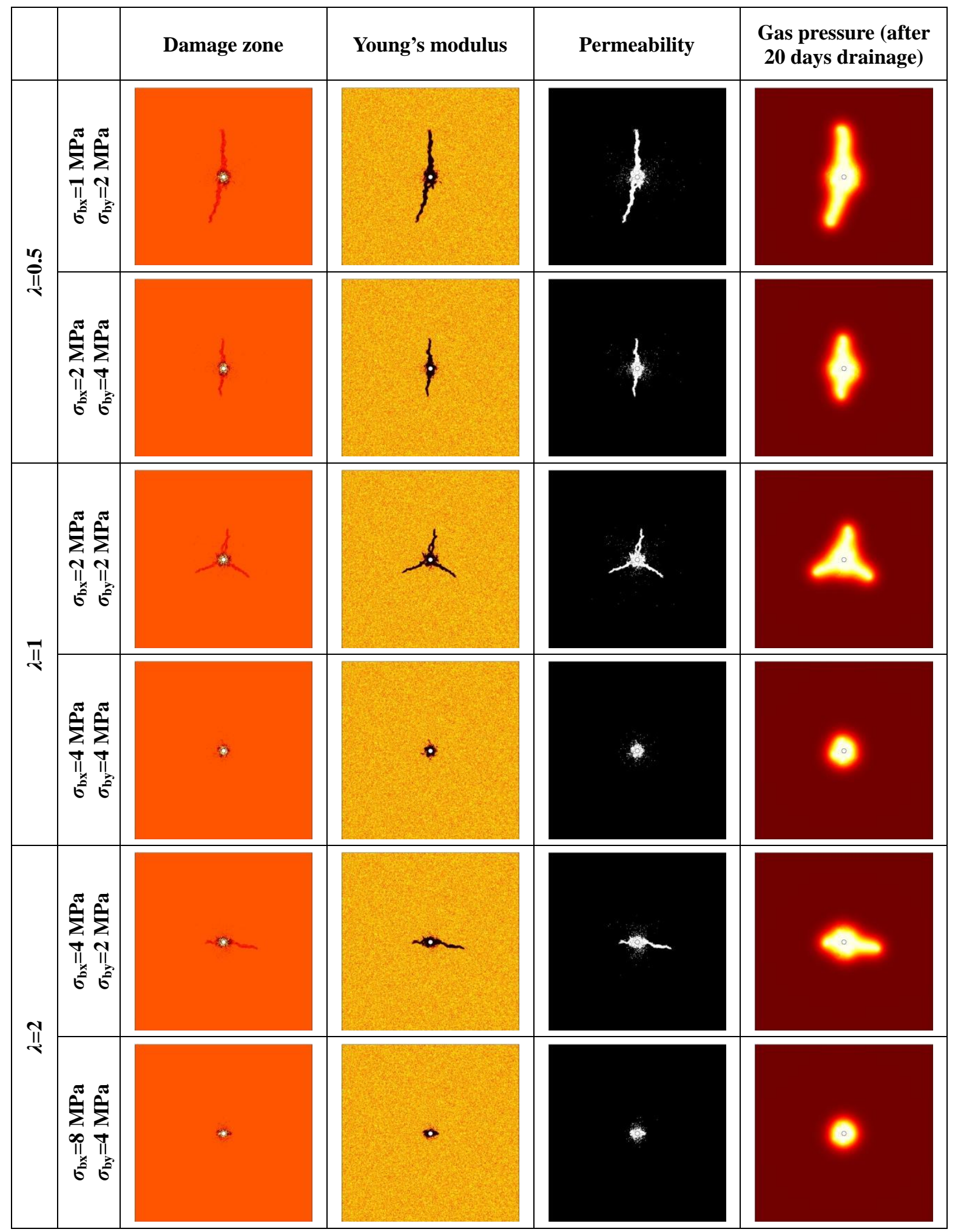

Fig.16 Damage evolution induced by high-pressure air blasting when different confining pressures are specified (numerical results) 


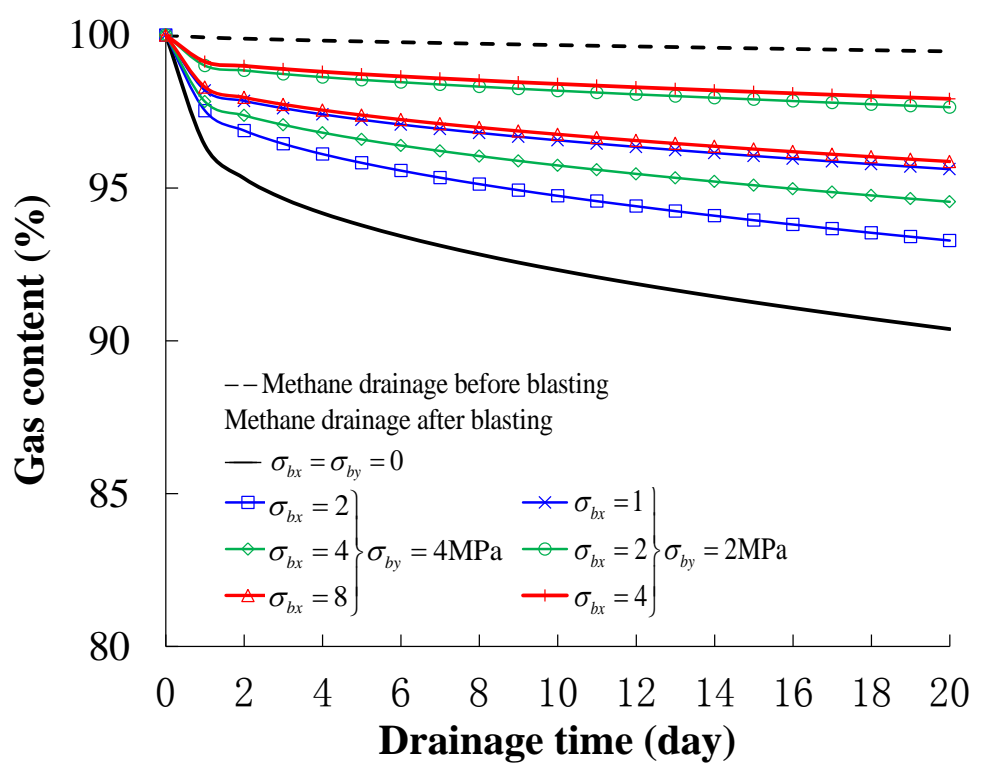

Fig.17 The relative gas content in the sample until 20 hours after drainage (numerical results) 